\title{
"O quanto é preciosa ao Compositor a Instrução Literária": o projeto criativo em Arte explicada do contraponto, de André da Silva Gomes (1752-1844)
}

Marcio Leonel Farias Reis Páscoa ${ }^{1}$

Universidade do Estado do Amazonas (UEA) mpascoa@uea.edu.br 


\section{Resumo}

A crescente produção de trabalhos acadêmicos, inclusive no Brasil, inspirados na teoria das schematae de Gjerdingen, em paralelo com a discussão no âmbito da teoria das tópicas musicais, a partir das ideias de Ratner, vem estimulando a busca de significados resultantes da interação entre aspectos sintáticos e semânticos da obra musical, especialmente aquela desenvolvida entre os séculos XVIII e XIX. Tais trabalhos, reunidos a partir da junção da musicologia com vários outros campos de estudo, na música ou fora dela, reacendem o debate sobre o uso da Retórica e da Poética como orientação dos projetos composicionais dos autores daquele período. Neste sentido, o presente artigo discute as estratégias criativas de André da Silva Gomes (1752-1844) à luz da sua Arte explicada do Contraponto.

Palavras-chave: Teoria TópicaMusical; André da Silva Gomes; Contraponto; Composição; Teoria e História da Música no Brasil.

\section{Abstract}

The growing output of scholar works, including in Brazil, inspired by Gjerdingen's schematae theory, in parallel with the discussion on the musical topic theory, after Ratner's issues, has stimulated the search for meanings resulting from the interaction between syntactic and semantic aspects in musical works, especially those ones developed between the 18th and 19th centuries. Such compositions, gathered from an amalgam of musicology with several other study areas, in music or related sujects, rekindle the debate about Rhetoric and Poetics as guidance for the compositional projects of authors from those times. In this way, the present article discusses André da Silva Gomes's (1752-1844) creative strategies of focusing his thoretical manuscript Arte explicada do Contraponto.

Keywords: Musical Topic Theory; André da Silva Gomes; Counterpoint; Composition; Theory and History of Music in Brazil. 
$\mathrm{Na}$ última década surgiram diversos trabalhos que apreciaram a música feita no Brasil entre a segunda metade do século XVIII e as primeiras décadas do século XIX, segundo abordagens teóricas recentes, mas que se valem da recuperação de procedimentos técnicos e ideológicos daquele tempo. Tais abordagens, mais queferramentas técnicas e analíticas, discutem o projeto artístico dos autores, tentando entender seu contexto criativo. Uma das mais inspiradoras, a proposta de Gjerdingen (2007), evidencia o largo uso do que ele chamou de schemata - esquemas galantes, ou esquemas de contraponto que, funcionando como fórmulas compositivas, erigiam a estrutura de uma composição. Por essa perspectiva se percebe que estes esquemas combinavam uma dada relação de intervalos com encaminhamento de graus, sem prejuízo da liberdade na construção do desenho musical, repleto de cadências, ornamentos e improvisação (GJERDINGEN, 2007). Há esquemas mais utilizados para a abertura de obras musicais, outros mais adaptáveis ao meio das peças e ainda outros mais adequados ao seu encerramento, mas nada disso é regra fechada, pois, a depender do tempo da composição e de certas especificidades de seu uso, quase todos os esquemas podem estar em qualquer parte da obra. Nem mesmo os estágios de combinação dos graus são disposições monolíticas e podem ser alterados pontualmente, sem prejuízo para sua compreensão e finalidade.

Gjerdingen aponta para o fato de que ouvintes, como os próprios compositores, eram, e podem ser, introduzidos ao processo de escuta e reconhecimento destes esquemas contrapontísticos, sem abordar necessariamente significados de ideias musicais; schematae não teriam valor semântico e portanto elas são "figuras" (termo que ele também usa) a serem consideradas num propósito sintático: se a música é uma linguagem que opera ideias, a estrutura fraseológica se valeria destas fórmulas discursivas para levantar os temas musicais (GJERDINGEN, 2007, p.16). A proposta de Gjerdingen está bastante relacionada à Cognição Musical e, por isso, pode-se vincular culturalmente a outras abordagens com as quais se pode combinar.

Tais elementos vieram reforçar a ideia de que esta época se constituía num período bem definido, a que alguns autores chamaram Período Galante, ou que pelo menos havia um estilo dominante, o Estilo Galante, compreendido no século XVIII, mas com extensões e consequências que atravessam para o século XIX (HEARTZ, 2003, p.1006).

A par disto, caminhou outra proposta analítica sobre o material musical do mesmo período que tem ganhado crescente interesse, desta vez chamando atenção sobre sua carga semântica e, por conseguinte, com grande repercussão sobre o modo de ver e pensar o projeto criativo musical. Ratner (1980) estabeleceu a teoria dos tópicos - ou tópicas - musicais ao discursar sobre categorias de tipos e estilos que impregnam as elaborações musicais, especialmente no que se convencionara chamar de Classicismo, que coincide com parte do período estudado por Gjerdingen e também do espólio musical brasileiro em questão. Ratner já se ocupava do assunto em 1957, quando afirmou que tipos e estilos correspondem às expressões idiomáticas, que ele vai chamar de tópicas musicais (RATNER, 1957 p.167). Posteriormente admitiu, de modo mais genérico, que se tratavam também de "materiais para a conversação musical" (RATNER, 1966, p.214) e chegou mesmo a concebê-los como temas, ao lhes atribuir a noção de elementos expressivos, ou figuras de expressão, de um vocabulário, uma vez que possuem 
significado próprio, lastreados por contexto histórico e cultural específico, Ratner os entendeu como munidos de poder argumentativo, formalizados em movimentos, seções ou peças completas, a que ele chamou de tipos, ou trechos estruturais ordenados e em progressão, que ele considerou como figuras de estilo (RATNER, 1980, p.9-30).

Os trabalhos de Ratner e Gjerdingen não seriam possíveis sem uma abertura maior do entendimento sobre musicologia e notadamente de estudos sobre percepção, cognição e análise, como, por exemplo, o de Meyer (1956, 1989) e aquele de Sanguinetti (2012) sobre os partimenti e os cadernos instrucionais, onde repousa a estratégia de ensino do arcabouço teórico usado na Itália, mormente em Nápoles no século XVIII, que remanesceu adiante, chegando a ser usada em lugares e tempos tão distantes quanto o Brasil do século XX.2

Por outro lado, se a obra de Gjerdingen também foi enriquecida por estudos paralelos e posteriores, a proposta de Ratner tem sido amplamente discutida, sendo consequentemente desenvolvida, criticada e reposicionada por uma série de autores, como Allanbrook (2014), Monelle (2006), Agawu (2008), Mirka (2008, 2014), dentre outros. Em seguida, Byros (2009, 2014) e Kisielewska (2016) argumentaram que nas obras deste citado período existe uma interação entre os esquemas de contraponto, suscitados por Gjerdingen, e as tópicas musicais, conforme o conceito evocado a partir de Ratner, permitindo perceber possibilidades comunicativas e significados que evidenciam projetos criativos mais profundos e complexos dos compositores do passado. Tais interações revelariam, portanto, o modo como o processo de mimesis decorreu na abordagem das ideias transformadas em obras musicais.

As práticas compositivas a partir da noção das schematae e a concepção criadora que se organiza em torno do que trata a teoria das tópicas musicais a partir de Ratner, ainda que possam ter sido usadas ao longo de todo o século XIX, ficaram obscurecidas por uma nova idealização musical e pela construção de um discurso ideológico específico de segmentos culturais do Romantismo e seus particulares interesses e maneiras de ver a música (GJERDINGEN, 2007, p.416).

Tal discurso selecionou uma narrativa a ser vencida. Por um lado, aquela dispersada a partir dos conservatórios napolitanos que chegaram ao auge no século XVIII, e, por outro, a da concepção geral sobre a validade do uso da Retórica e da Poética, com sua discussão central sobre a mímesis - e desde aqui uma idealização a partir da herança da cultura clássica de orientação greco-romana -, uma vez que não serviria à noção de autonomia da música que se pretendia como disciplina em molde científico.

Foi então absolutamente legítima a indagação de pesquisadores brasileiros sobre a música praticada no espaço da lusofonia, diante das sabidas conexões de Portugal e Brasil e destes com a matriz italiana. A despeito de catástrofes e de incúria que devastaram o patrimônio musical lusófono, passaram a ser reconsiderados muitos elementos já conhecidos que o podem reconectá-lo a outros eixos de pensamento e ação musical.

2 O partimento constava do programa de provas de harmonia nos exames do Conservatório de Música do Instituto de Bellas Artes do Rio Grande do Sul em 1932. Ver Federação, 14 abr. 1932. 
Uma das questões candentes repousa sobre que nível de consciência do uso dos procedimentos criativos, no âmbito da discussão que envolve esquemas e escolhas tópicas, os autores que trabalharam no Brasil tinham. Parece haver pouca densidade de material crítico para esta finalidade. Mas, ao menos, o que existe serve ao debate e permite reflexão. Assim, o objetivo deste escrito é contribuir para posicionar a produção lusófona na discussão do tema, buscando entender a perspectiva de sua própria tradição criativa.

\section{O projeto criativo em André da Silva Gomes}

Dentre os compositores ativos no Brasil do período 1750-1830, o caso do português André da Silva Gomes (1752-1844) é sempre interessante, por fazer a conexão entre a metrópole e a colônia. Nascido em Portugal, onde obteve a formação musical, veio para o Brasil integrando a relação da família do bispo Frei Manuel da Ressurreição, que em outubro de 1773 obteve passaporte para se dirigir a São Paulo através do Rio de Janeiro (DUPRAT, 1995, p.60). Em São Paulo, Gomes assumiu os deveres musicais da Sé como seu quarto mestre de capela, tendo servido ainda como regente na Casa da Ópera. Fora da música, foi também, por designação do bispo, nomeado professor de Gramática Latina. Casara-se logo em 1775 com Maria Garcia de Jesus e, sem filhos naturais, se responsabilizou por uma enteada e grande número de menores, alguns deles legalmente adotados (DUPRAT, 1995, p.58). Também assentou patente de capitão em 1789 (DUPRAT, 1995, p.70), chegando ao posto de tenente-coronel, vindo a servir no governo provisório paulista em 1821, após a Independência do Brasil.

Toda a sua vida profissional musical se deu em São Paulo, onde deixou cerca de 130 obras, escritas ao que se sabe num período que vai de sua chegada em 1774 até 1823 , ano de uma Missa de Natal composta quando de sua estada em Cotia. Quase toda a sua música, sendo mormente religiosa - a despeito de ele ter estado a trabalhar também na Casa da Ópera -, repousa desde longo tempo na Cúria Metropolitana de São Paulo e no Centro de Letras e Artes, em Campinas, pela cópia de Manuel José Gomes (1792-1868).

Entretanto, dele apareceu mais tarde um fragmento do que pode ter sido um dos exemplares mais extensos da tratadística em língua portuguesa.

No final do século passado, surgiu em Itu (SP), no espólio do compositor Elias Álvares Lobo (1834-1901), um manuscrito intitulado Arte Explicada do Contraponto Dividida por Lições em Trez Tomos, copiado por Jerônimo Pinto Rodrigues e pelo próprio Lobo, que o atribuíram a André da Silva Gomes. Pinto Rodrigues nasceu em São Paulo, onde foi batizado em 1790, sendo filho e neto de mestres de capela igualmente de Itu. Tornou-se professor de música na mesma cidade e teve por aluno o jovem Elias Álvares Lobo (DUPRAT et al., 1998, p.9-10).

O tratado, cuja cópia sobrevivente data de 11 de abril de 1830, deveria originalmente estar composto de três partes. Consta, infelizmente, apenas o primeiro tomo, intitulado Preceitos do Contraponto Simples e Figurado, sem que se conheça até o presente o conteúdo dos demais volumes, restando apenas os títulos. O tomo 2 foi intitu- 
lado Preceitos Concernentes à Pura Composição e o tomo 3 chamou-se Exemplos de todos os preceitos, numerados pela ordem das Lições.

Gomes parece dar por resolvido de modo mais eficiente e mais simples o que exaustivas discussões feitas a partir da proposta das tópicas de Ratner têm avançado. Obviamente que tais discussões puseram a descoberto um leque vasto de questões, mas ainda de equívocos e dificuldades conceituais, longe de deixar o assunto em águas claras. Gomes define sua metodologia criativa, propõe articulação coerente e objetiva do processo inventivo e mostra que o debate atual precisa se deslocar para o campo da mimesis e dos conteúdos relativos à Poética, sem perda de conexão com a Retórica. Isto implica ainda num direcionamento mais interessante do que a discussão concentrada apenas na Retórica ou à volta dela, feita por alguns segmentos intelectuais atuais, mesmo que baseados em fontes históricas.

De antemão, na primeira lição do tomo sobrevivente, o autor oferece sua definição de contraponto, que, para além de mencionar as espécies e a perfeita "concordância harmoniosa de vozes", revela que Gomes se orientava pela ideia da junção de partes que resultam em melodia e harmonia, "isto é, proporcionado ajustamento de Números e suave recreio do Ouvido" (DUPRAT et al., 1998, p.17). Como seria notado por quem se debruçou sobre o manuscrito, tal noção de contraponto inclui a estruturação musical com suas regras de harmonia inclusas, ideia vinculada à teoria musical do século XVIII (LANDI, 2006, p.32) e à teoria crítica sobre a música deste mesmo tempo (RAMOS, 2014; CHRISTOVAM, 2017). Gomes avança a reflexão conceitual dizendo que o contraponto é a "Invenção da Harmonia competente a uma, duas ou mais partes" (DUPRAT et al., 1998, p.17), introduzindo o termo da organização discursiva prevista na Retórica.

Gomes diverge o conceito do contraponto do de composição. Para o primeiro diz se tratar de "Invenção das cantorias competentes a cada uma das partes" e explica: "Eu suscito na minha Fantasia uma Cantoria, eis aqui a Composição; porém careço modificá-la com os preceitos, eis aqui o Contraponto" (DUPRAT et al., 1998, p.17).

O Vocabulário de Raphael Bluteau (1638-1734) diz que Fantasia é palavra grega que significa imaginação (BLUTEAU, 1728-1732, v.4, p.32), mas alerta que, mesmo que possam ser consideradas o mesmo, "diferem em que a imaginação forma a imagem, que recebeu dos sentidos exteriores, [enquanto] a fantasia discorre e faz seus discursos, ainda que imperfeitos" (BLUTEAU, 1728-1732, v.4, p.54). O dicionarista também confirma que se entende a imagem como sinônimo de figura e de "uma representação dos cinco sentidos exteriores naturalmente ou também sobrenaturalmente" (BLUTEAU, 17281732 , v.4, p.54). Fica assim mais claro entender que, para Gomes, a elaboração discursiva que a fantasia suscita é aquela estimulada pelos sentidos, aqui entendidos como percepção do mundo natural ou manifestação sensorial de um sentimento. Essa figuração, a que se pode chamar agora musical, é ordenada pelo regramento que o contraponto traz. Esta representação do que vem na mente éa expressão (BLUTEAU, 1728-1732, v.3, p.395), também considerada como a Elocução ou Pronunciação (BLUTEAU, 1728-1732, v.3, p.395), ou seja, parte constitutiva do discurso a ser organizado. Na sua consideração geral sobre a música do século XVIII, Ratner considerou que muitas destas expressões 
seriam reconhecíveis pelos ouvintes musicais e que esta condição dava às expressões uma qualificação, considerando-a uma tópica.

Todas estas expressões [de um idioma] eram familiares ao ouvinte do século XVIII. Ele se deleitava em observar como um compositor as manejava durante uma composição; ele, bem como o compositor, apreciava a riqueza de conteúdo que a interação destes vários estilos provia. E, quanto melhor ele conhecesse a linguagem musical da época, mais agudo seria seu julgamento a respeito da habilidade e imaginação do compositor. Ele poderia reconhecer a frase melódica elegante e persuasiva, o movimento do gesto harmônico, o contraste efetivo bem colocado, e poderia distingui-las da música que era trivial, diluída e inadequada. ${ }^{3}$ (RATNER, 1957, p.176, tradução minha).

$\mathrm{Na}$ teoria de Ratner, o reconhecimento da tópica pelo ouvinte é condição fulcral para o conceito e, como se vê em Bluteau e Gomes, ela poderia estar mais próxima do que se entende por uma representação. Mas o termo tópica, no campo da retórica clássica, se refere a algo mais lateral, como lugar-comum (mas também lugar comum), ou métodos e estratégias para a escolha de assuntos que podem conter os materiais expressivos a serem usados e ainda assim se relacionar com a etapa da Inventio (ALLANBROOK, 1983, p.329; RUMPH, 2012, p.81). A tópica poderia ser então ponto de recolha de elementos de inspiração, circunscrição de campos onde características de um idioma ou porções conceituais estão presentes, ou ainda as ferramentas, métodos e conjunto estratégico com seus materiais para aplicação, dentre outras possibilidades de uso em que foram empregadas nos escritos de Estudos Clássicos.

Ainda sobre a Fantasia, Bluteau confirma, como já dissera sobre a imaginação, que "é a segunda das potências que se atribuem à alma sensitiva, ou racional, que forma a imagem das coisas" para arrematar que a Fantasia "é a Harmonia, que não tem nome certo, mas sai do gênio e da habilidade do compositor" (BLUTEAU, 1728-32, v.4, p.32).

Repara-se então que a ideia de Fantasia para Gomes não é a limitação de uma categoria expressiva, vista no discurso atual da teoria das tópicas, mas, acima de tudo, a propriedade onírica da representação da mimesis.

\section{Articulações com a Mimesis}

A discussão que a primeira lição do tratado de Gomes suscitou aqui está muito relacionada à teoria da mímesis. Percebe-se que ela é entendida em Bluteau e Gomes tal como Aristóteles a tomou de Platão: a coisa representa a ideia, mas não tenta se passar por ela (PALUMBO, 2008, p.10). Gomes fala que a imitação pode se valer não somente "do vigor da Natureza" (DUPRAT et al., 1998, p.101), mas pode ser "aquela por meio da qual ele [o compositor] se propõe a imitar o gênio, o estilo e a demarca daque- 
les Mestres, que forem reconhecidos grandes e famosos nesta Faculdade aos quais há toda necessidade de imitar" (DUPRAT et al., 1998, p.100). Diz ainda que não devem ser atendidos os presunçosos que acham que podem abrir mão desta experiência por chamarem-na de servidão, porque reconhece que "nosso gênio por mais feliz que ele seja, tem necessidade de socorros estranhos [de terceiros] para se nutrir e dilatar" (DUPRAT et al., 1998, p.100).

Não há como deixar de pensar no paralelo entre este entendimento de Gomes com aquilo que Ratner pensou serem as tópicas musicais, os estilos, tipos, expressões, que percorrem as obras musicais e se consagram no vocabulário à disposição dos compositores. Gomes parece ir neste sentido ao dizer que "a nossa alma jamais só de per si pode conceber, gerar e apresentar uma produção célebre se ela não tiver sido fecundada primeiramente por um abundante Manancial de Conhecimentos" (DUPRAT et al., 1998, p.100). Ora, se o Manancial de Conhecimentos de Gomes for o repositório de inspiração, como o lugar que Allanbrook mencionou (ALLANBROOK, 1983, p.329), ou se ele é/contém o ferramental e o modelo estratégico de abordagem do compositor, como na discussão dos autores clássicos da Antiguidade, as análises de sua obra, procedimentos e fontes devem comprovar.

Gomes prevenira que a Composição deveria ser ajustada pelos preceitos, dizendo "eis aqui o contraponto" (DUPRAT et al., 1998, p.17). Em termos práticos, ele dispõe os conteúdos das regras no que organizou como lições, e os preceitos são as suas explicações procedimentais. O preceito, ou a "regra d'arte" (SILVA, 1789, p.486), é o que opera a existência da obra, estabelecendo a noção de que a estrutura é como o esqueleto que serve à figuração/imagem/objeto, pois, para André da Silva Gomes, a composição trata da "disposição e realce da Cantoria competente a cada uma das partes" (DUPRAT et al., 1998, p.17). No seu entendimento, a Cantoria, sendo um concerto de vozes, música vocal ou com partes cantáveis, está sujeita ao Contraponto, "a Invenção dos Números Harmônicos competentes a todas as partes" (DUPRAT et al., 1998, p.17), ou seja, sujeita aos tons musicais, assim chamados de números harmônicos porque têm medida (BLUTEAU, 1728-32, v.5, p.771) e, portanto, vão dando forma à ideia.

Neste exato momento, como se não quisesse que o seu leitor se confundisse sobre o que estava sendo falado, Gomes faz uma nota à sua Lição 1a.

\footnotetext{
Daqui pode concluir o Compositor instruído, não só como Filósofo, a entidade diferente de cada um dos sobreditos empregos, podendo justamente distinguir o Contraponto Harmonia Docente e a Composição Harmonia Utente, isto é, para que se dá preceitos e parte que os apresenta em execução; mas também pode observar como Retórico a analogia da Faculdade Harmônica com Faculdade Retórica; aqui se observa o Contraponto relativo à parte da Invenção e a Composição relativa à Disposição e à Elocução. Na Dissertação que serve de princípio a esta obra fica após demonstrado quanto é preciosa ao Compositor a Instrução Literária. (DUPRAT et al., 1998, p.17).
}

A instrução literária ao tempo de Gomes era uma instrução concernente às Humanidades, uma vez que as Letras ou demais Ciências Humanas aí se encontravam numa mesma Faculdade(BLUTEAU, 1728-1732, v.5, p.158), poisentendia-se a Literatura como 
sinônimo de Erudição e Ciência (BLUTEAU, 1728-1732, v.9, p.562), sendo o literato portanto o douto, o ciente, consequentemente, aquele que é versado nas Letras (BLUTEAU, 1728-1732, v.9, p.562). A instrução literária era então a doutrina das Humanidades e, sobretudo, da construção da ciência; a Faculdade Retórica, de que Gomes faz menção, abrangia assim toda a construção de conhecimento que faz uso da linguagem, entendendo-se aqui ser verbal ou musical.

Gomes diz ser o Contraponto a Harmonia Docente, ou seja, a harmonia aprendida, regrada por preceitos, portanto submetida a regras, enquanto defende ser Composição a Harmonia Utente, o que, como já visto, é elaboração de materiais vindos da imaginação de quem cria livremente. A faculdade utente, portanto, seria organizada pela doutrina docente, ou seja, a Composição organizada pelo Contraponto, gerando a ideia de que há neste último uma carga sintática que se articula ao poder semântico da primeira. Esta articulação vem justamente do modo como ele conceitua e da analogia do Compositor com o Retórico, ou seja, a compreensão do ofício de compor passa pela mesma instrução geral de todas as Humanidades, a instrução literária. Assim, a construção ou composição musical é portanto a construção ou composição de um discurso, tal como o literário. É neste ponto que se torna legítimo pensar que às tópicas musicais de Ratner e seguidores se combinaria a esquematização do contraponto, não só conforme a teoria tradicional (como vista em Fux ou nos autores napolitanos), mas adensada pela prática observada por Gjerdingen, resultando em uma interação.

Ao dizer que o Contraponto é a parte relativa à Invenção e que a Composição se relaciona à Disposição e à Elocução, Gomes causa alguma confusão por dar a entender que a doutrina regrante, a dos números (tons) harmônicos, para usar seus termos, pode ser associada à seção criativa, inventiva da elaboração do discurso literário. Mais uma vez é necessário recorrer ao contexto correto de compreensão.

A Invenção é, sobretudo no ensino clássico de verniz religioso, o modo de obrar as palavras, pois "verdadeiras invenções são as que Deus revela; que a dos homens são observações de coisas naturais, de inferências fundadas nelas, vg. a Pintura..." (BLUTEAU, 1728-32, v.4, p.181). Ora, como já se pode deduzir, o produto da inventio, o invento, não se põe de pé sem o contraponto que dá regra à composição, sendo esta finalizada na maneira como se a organiza e como se a interpreta.

Se Gomes alerta que o Compositor deva proceder como Retórico, se refere àquele que faz "profissão de falar de repente [de improviso], sobre qualquer matéria [tema, assunto, ideia] que se lhes proponha" (BLUTEAU, 1728-32, v.7 p.305-306), sendo assim alguém que tenha entendimento geral das coisas e domínio de estratégias comunicativas. Retórico é o mestre que professa e ensina Retórica, que sobretudo necessita de usar da Elocutio, pois

[...] para Cicero a Eloquência [do retórico] é filha do entendimento [compreensão do assunto, pois ao retórico não cabe apenas compreender o que está falando, mas convencer, comunicar, comover o ouvinte através da eloquência]... levantar com expressões nobres e figuras a humildade dos seus conceitos. (BLUTEAU, 1728-1732, v.7p.305-306). 
Gomes diz que existem ainda outros preceitos que não os do contraponto e que são aqueles de que o compositor, para se valer da Natureza e dos Mestres, precisa

[...] saber manejar para que se consigam estas vantagens, os preceitos desta Imitação, que se difere de um empréstimo de ideias, de pensamentos, de sentimentos e passagens dos escolhidos exemplares, que nos propomos a imitar, ou aproximando-nos ou diferenciando-nos, ou diminuindo ou aumentando. (DUPRAT et al., 1998, p.101).

É aqui que ele colmata que o projeto criativo se vale de "preceitos próprios da Faculdade Retórica e Poética, nos quais supomos o nosso aluno de Composição de Música bem instruído, como preparatórios desta Faculdade, que tratamos, por isto deixamos aqui de os explicar" (DUPRAT et al., 1998, p.101)

Fica muito claro que tanto a Retórica quanto a Poética eram de fato usadas no processo de criação, tanto quanto no de aprendizado e elaboração musical, havendo procedimentos próprios (preceitos) de operacionalizar as normas (regras) pertinentes ao discurso.

\section{Lógicas e discursos recuperados e a recuperar}

A ausência dos tomos 2 e 3 da obra de André da Silva Gomes infelizmente impede que nada mais se conheça para além das regras de contraponto, tal como a sabemos. $O$ tomo 2, que se intitulou Preceitos Concernentes à Pura Composição poderia trazer aspectos de escolha temática, estilística e de gênero, mediante algum tipo de ordenação com provável orientação de Retórica e Poética. O Tomo 3, nomeado Exemplos de todos os preceitos numerados pela ordem das lições, deveria ser algo próximo de um zibaldoni e incluir elaborações musicais tais como os partimenti, os solfeggie exemplos fugais. Os dois últimos tomos poderiam assim conter mais aspectos sobre Disposição e Elocução, até mesmo a concordância com eventual figuração retórica, pois Gomes, nas restantes lições do Tomo 1, também já se ocupa de cláusulas e cadências. Independentemente disso, seria valioso poder ver o modo como o autor articularia as explicações sobre o processo criativo dos tomos 1 e 2 com o volume de exemplos, em que podiam constar desde esquemas até peças completas. De modo geral, a obra de Gomes articula tudo, como um retórico o faria: as etapas do discurso como partes da elaboração da obra, ou seja, criação, regramento, disposição e elocução, e estas são vistas na perspectiva entre compositor, intérprete e ouvinte, não necessariamente três pessoas diferentes, mas três condições distintas de lidar com a arte.

Mesmo que não haja no ambiente lusófono, e mesmo mediterrânico, tratados nos moldes semelhantes ao que se desenvolveu no mundo germânico durante os séculos XVII e XVIII, a presença da Retórica e da Poética no planejamento compositivo musical deve ser vista com imenso cuidado.

Cerca de 15 autores alemães se ocuparam do assunto, entre eles, Burmeister (Hypomnematum Musica Poetica, 1599) e Forkel (Allgemeine Geschichte der Music, 1788-1801), incluindo alguns a que hoje muito se recorre, como Mattheson (Das Neu-E- 
roffnete Orchestre, 1713; Der Vollkommene Capellmeister, 1739), mais por dependência decorrente de mentalidade positivista do que por necessidade de compreensão de uma mentalidade ou sistema intelectual em particular. A intenção deste último em trazer conceitos da Retórica Clássica a um nível mais básico de compreensão, ainda que no âmbito de uma elevada intelectualidade, parece encontrar amparo no ideal iluminista da aprendizagem orientada pela leitura, sequenciada até níveis mais complexos em alguns casos. No norte europeu, mais industrializado e com comércio mais intenso de publicações, houve para toda a sorte de assuntos a edição de inúmeros manuais, tutores e publicações correlatas a serviço de uma emancipação, se possível por autoaprendizado ou a partir deste. O objetivo era fazer com que o diletante ou curioso, termo este muito usado no ambiente luso-brasileiro para amador instruído, pudesse adquirir fluência de conhecimentos em algum nível.

O estudo musical no mundo lusófono foi sempre desenvolvido no âmbito de influência de instituições religiosas, o que inclui as irmandades e confrarias, de par com o estudo de Filosofia Moral e Retórica, como disciplinas separadas e desenvolvidas num conjunto de saberes de formação humanística. Assim, a proximidade dos assuntos na formação do indivíduo bem poderia prescindir de obras que explicitassem certas associações de ideia ou elaborações assertivas, que por vezes se revelariam contraditórias, como a atribuição afetiva de tonalidades ou a demonstração figurativa de equivalentes literários em música.

A sistematização germânica, como a tentativa de definir a figuração musical numa tradução direta das figuras de retórica, parece ser uma estratégia de percepção e aprendizado de valores culturais, que no ambiente mediterrânico seriam possivelmente mais imanentes, estariam mais enraizados nos seus praticantes e compreendidos em um âmbito mais conceitual. O contexto norte-europeu, com desenvolvimento mais acelerado do capitalismo e uma cultura burguesa pressionando pela disseminação e a compreensão de conhecimento como bens de consumo direto ou indireto, teria permitido e estimulado a publicação de materiais educativos e informativos em favor do ideal emancipatório individual e até mesmo com vistas à democratização do conhecimento e, consequentemente, do Poder. No sul, menos afetado por um desenvolvimento industrial e regulado por outra hierarquia social com outros valores, a tradição de circulação de determinados conhecimentos, de muito enraizada e ainda pertencente a modelos que têm a Igreja por referência, prescindia destes sistemas e estruturas como aprendizado.

Percebe-se, por exemplo, que a dinâmica da impressão bibliográfica e musical foi muito mais modesta no âmbito lusófono, onde o desenvolvimento do mercado editorial se verificou mais tardiamente, ou seja, em direção do final do século XVIII, sendo mais incomuns os suportes culturais, como o livro impresso, a gravura e a partitura editada.

Assim, modelos de pensar e transmitir conhecimento sobre música também geram possibilidades diferentes de fazer música. A mudança de modelos compositivos, associados com o que se chama Estilo Galante, deu-se concomitantemente à mudança de pontos de vista sobre música. No caso germânico, uma vezque parte dos conteúdos explicados por Mattheson e outros foi superada pelos seus sucedâneos, com uma visão 
mais centrada na discussão sobre a mimesis, não se deveria esperar encontrar o mesmo tipo de conflito nos escritos da cultura musical de orientação italiana.

Isso não quer dizer que não houvesse consciência desse processo da mimesis, como se percebe nas explicações de Gomes. Deve-se considerar então que o lluminismo atingiu o espaço mediterrânico num outro nível de preocupação com a ciência. $\bigcirc$ fato de não haver publicações em nível interpretativo de tais ideias, como a do campo da Retórica Musical, não quer dizer que o assunto não estivesse a ser tratado. Ao contrário, manuscritos diversos apontam para ampla presença cultural dos modelos napolitanos no restante da Europa e neles, como se pode ver, o assunto está inserido.

A existência de cadernos de partimenti e solfeggi no meio lusófono aponta na direção do modelo de ensino conservatorial desenvolvido em Nápoles, que revela uma visão mais ontológica e menos compartimentada ou fragmentária da Música.

Como se pode ver no caso de André da Silva Gomes, podem ser encontrados teóricos e compositores neste âmbito lusófono ou mediterrânico sem vinculação aparentemente nenhuma com modelos e abordagens tais como expostos em Mattheson, por exemplo, e no assunto em questão, mas que parecem ter ciência do processo de criação e interpretação de ideias musicais incluídas no campo da Retórica e da Poética.

Inclusivamente, existe o fato de que o ambiente urbano industrializado do norte europeu despertou para a discussão sobre a flutuação de Ethos e Afeto na sua representação em música, justamente por causa da artificialidade da convenção e em favor de um fluxo natural de sentimentos e ideias. Nesse contexto, o entendimento de um caráter monolítico, fixo e estático numa obra musical passa a ser superado de meados do século XVIII em diante e com ele uma parte da visão de origem cartesiana que orientou muitas obras. A ideia da Arte como representação do Natural, no modo cartesiano de entender, encontrou grande defesa em obras como a de Rameau, o célebre Traité de l'harmonie, de 1722. O lado científico racionalista que gerou obras como essa já era também eco ressonante da Musurgia Universalis, de Athanasius Kircher (1650), um teórico de notável envergadura que viveu enorme parte de sua vida na Itália, tendo escrito largamente sobre quase tudo e para quem os Afetos são resultantes do fluxo nervoso, por onde correm os aspectos espirituais da alma, estimulando o processo fisiológico. Foi por entender que o fluxo nervoso estimula, ou seja, age sobre o processo fisiológico do indivíduo, que Mattheson legitimou sua concepção de que o movimento musical resulta em comoção (MATTHESON, 1739) e de que os Afetos estão ligados a uma comoção estimulada por aspectos musicais a que o ouvinte foi exposto.

Mas o debate avançaria muito além. Se estes estímulos partem do aspecto fisiológico em si e apenas bastaria o som para despertar a afeição, temos a música admitida como linguagem, comunicando e evocando paixões, o pathos como expressão, promovendo um fluxo de ideias e sentimentos. Esta reflexão de Rousseau vai amplamente representada numa passagem literária sua:

Mas quando, depois de muitas árias agradáveis, chegaram estas grandes obras de expressão, que sabem excitar e pintar a desordem de paixões violentas eu perdi paulatinamente qualquer ideia de música, canção e imitação; eu acreditei que 
estava ouvindo a voz da dor, da paixão, e do desespero; eu acreditei ver mães enlutadas, os amantes traídos, e tiranos furiosos, e na agitação que fui forçado a experimentar eu dificilmente podia me conter em meu lugar. Eu sabia então por que essa mesma música que tinha uma vez me entediado agora me excitou à exaltação; é que eu tinha começado a compreender, e tão logo ela pudesse agir, ela agiu com toda sua força. ${ }^{4}$ (ROUSSEAU, 1764, p.283, tradução minha).

O trecho literário em questão vem de Julie ou La Nouvelle Heloise, um grande sucesso editorial de sua época, pois, antes de findar o século XVIII, já havia sido editada 72 vezes, sendo considerada uma precursora do Romantismo. Tal trecho já havia sido destacado por Sulzer, conforme lembrou Mirka (2014, p.14), porque, para ele, Rousseau foi além na doutrina da mímesis ao não considerá-la mera imitação musical, estendendo o seu alcance aos objetivos, quando se percebe que as paixões não são meramente reconhecidas, mas impactam o ouvinte por simpatia/empatia (Theilnehmung) à dor ou alegria de outro que a vive.

Ao fluxo emotivo, e desde já de ideias representadas, não cabe mais a noção de que, por exemplo, uma tonalidade seja constrangedora de um só afeto para todo um movimento de obra musical; isto seria uma mera convenção que passou em algum momento do século XVIII se desacreditou como representação de ideias e coisas. Isto porque o Afeto não sendo, portanto, estático, está sujeito à variabilidade, alternância, troca, mutação e fluxo. Ou, como diria Rousseau, que o compositor não deve somente representar as coisas, mas excitar a alma em direção ao mesmo movimento que nos permite vê-las e senti-las (MIRKA, 2014,p.33).

Ao final do século XVIII, uma importante obra compilatória como a de Sulzer (17921794) já consagrava que a música é movimento e, nisso, estabelecia os parâmetros musicais que promovem o fluxo dos sentimentos: 1) Progressões de harmonia, mesmo sem considerar o metro; 2) Metro (medida) pelo qual todo tipo de caráter geral de movimento pode ser imitado; 3) Melodia e ritmo, que, mesmo sem harmonia, são capazes de retratar a linguagem das emoções; 4) Mudanças dinâmicas nas notas podem contribuir para expressão; 5) Acompanhamento e mesmo a mistura de instrumentos escolhidos para acompanhar a música; 6 ) Modulação e digressão para e de tonalidades distantes (SULZER, 1792-1794, v.1, p.272-273 apud MIRKA, 2014, p.15).

A noção de Sulzer também pode em alguma medida lembrar o sentido das tópicas no ambiente da retórica tradicional (não as musicais, de Ratner), onde se veem os tipos comuns de meios e métodos a servirem de motor para ação argumentativa, tal como disse Allanbrook, neste caso especial refletindo Curtius, que o topos - a tópica - está num nível mais baixo de organização do tema (no caso, da composição como invenção), sendo mais imediatamente e amplamente consumível (ALLANBROOK, 2014, p.97).

$4 \quad$ Original: "Mais quand, après une suite d'airs agréables, on vint à ces grands morceaux d'expression qui savent exciter et peindre le désor- dre des passions violentes, je perdais à chaque instant l'idée de musique, de chant, d'imitation; je croyais entendre la voix de la douleur, de l'emporte- ment, du désespoir; je croyais voir des mères éplorées, des amants trahis, des tyrans furieux; et, dans les agitations que j'étais forcé d'éprouver, j'avais peine à rester en place. E connus alors pourquoi cette même musique qui m'avait autrefois ennuyé m'échauffait maintenant jusqu'au transport; c'est quej'avaiscommencédelaconcevoir, etquesitôtqu'ellepouvaitagirelleagissaitavectoute saforce"(ROUSSEAU,1764,p.283). 
Mas, ao considerar melodia, metro e harmonia e as dinâmicas que disso podem derivar, Sulzer está ecoando muito do próprio Rousseau, desde a Lettre sur la musique française, onde o filósofo francês exalta a música italiana pelas suas características naturais de, em imitação ao idioma italiano, suscitar os mais diversos sentimentos e poder dizer de modo apaixonado diversos assuntos (ROUSSEAU, 1753, p.18-24;31-32).

\section{Considerações finais}

Rousseau facilita em sua obra a ideia de que o contexto italiano prescindiria da crise de entendimento criativo que se discute sobre a música norte-europeia, porque na tradição mediterrânica, colmatada pela música italiana, a música se realiza de modo natural e bem-sucedido. Isto seria fundamental para o sucesso do modelo napolitano conservatorial, com sua forte estratégia de ensino-aprendizado e comunicação-expressão, que firmou sua grande expansão e capacidade de adaptação a contextos vários porque sua eficácia em promover a atividade musical contribuía para o ideal emancipatório de verniz iluminista.

André da Silva Gomes sabia pertencer a essa tradição e só ela lhe havia bastado quando afirmou estar "seguindo invariavelmente a doutrina e uso do nosso Sábio e experimentado Mestre o Sr. José Joaquim dos Santos, Mestre do Seminário da Patriarcal de Lisboa, e insigne hoje e singular nesta qualidade de Composição" (DUPRAT et al., 1996, p.96).

José Joaquim dos Santos (1747-1801) foi igualmente teórico e compositor, a serviço do Real Seminário da Sé Patriarcal de Lisboa, instituição que funcionou nos modelos romano e napolitano sobreditos, por orientação decisiva de D. João $V$ e D. José I, durando de 1713 a 1834 (sucedida então pelo Conservatório Nacional de Lisboa). Foi recrutado aos seis anos de idade, na Vila de Óbidos, onde nasceu (mais precisamente no Sitio do Senhor da Pedra), para entrar no Seminário da Patriarcal, ao lado de outros quatro meninos da mesma localidade. Ali teve formação regular de interno, concluída em 1763 com proveito suficiente para o convite que se seguiu, de integrar o corpo docente da instituição como mestre de Solfa, inclusive residindo na instituição (VIEIRA, 1900, v.2, p.274-276). Santos deve ter sido exclusivo do Seminário até 1768, pelo menos, quando deu entrada na Irmandade de Santa Cecília (que se reorganizara quase uma década antes), organismo regulador da atividade musical profissional em Lisboa, certamente motivado por propostas de trabalho oriundas de diversa origem, o que o levou a certa proeminência no meio musical, haja visto que se tornou diretor da irmandade entre 1794 e 1799 (VIEIRA, 1900, v.2, p.274-276). Santos escreveu pelo menos 65 partimenti que alcançam alta complexidade, e é muito provável que ele tenha influenciado uma geração inteira de grandes músicos no seu tempo.

Por outro lado, consta que Santos tenha sido discípulo do compositor napolitano David Perez (1711-1778) quando da mudança deste para Portugal em 1752 (VIEIRA, 1900, v.2, p.274-276), na condição de mestre de música das infantas. Esta posição era a mais elevada para um músico na Corte, por estar ao acesso dos monarcas e por poder 
formar a futura geração coroada, condição que obviamente permitiu a David Perezlarga influência sobre a música operística e religiosa no reino.

Este é o mesmo Perez que Rousseau evoca na citada carta ao dizer que ele é um dos compositores da música italiana que, com sucesso, manejou a "audácia da modulações", "menos preparadas mas mais agradáveis e perceptíveis, juntando viva energia e expressão", exprimindo "as reticências, as interrupções, os discursos entrecortados que são a linguagem das paixões” (ROUSSEAU, 1753, p.31, grifo meu).

Perez, nascido e com formação musical em Nápoles, foi aluno do conservatório de Santa Maria di Loreto de 1722 a 1733, aplicando-se em canto, violino, cravo e contraponto. Afamado pelas dezenas de óperas, foi talvez ainda mais produtivo no campo da música sacra, deixando também alguma música instrumental. A sua obra didática que sobreviveu em Portugal, onde viveu por 26 anos até sua morte, corresponde a mais de 40 partimenti que estão distribuídos ou repetem-se em cerca de oito cadernos pertencentes a fontes diferentes, onde integram volumes de Regras (TRILHA, 2010, p.263264). Dele ainda remanescem alguns cadernos de Solfeggi, sendo alguns muito afamados pela Europa e publicados até o século XIX, como os Solfeggi d'Italie, que tiveram várias reimpressões.

Os partimenti de Perez e Santos fazem parte de uma sequência de estudos que se vincula à linha do compositor e internacionalmente afamado professor Francesco Durante (1684-1755), que envolvia cadências, a regra da oitava, os partimenti desde os mais simples até os que envolvessem imitações as mais complexas (GJERDINGEN, 2007, p.225).

Mesmo que não haja vínculo formal documental direto entre Perez e o Seminário da Patriarcal, onde Santos e Gomes estudaram, isto não deve ser um impeditivo para considerar sua influência sobre os estudantes de música desta escola. Havia aulas vespertinas que não ficaram registradas nos assentamentos sobreviventes daquela instituição, mas que eram aparentemente muito mais concorridas que as matrículas regulares no internato, por serem, além de abertas ao público, isentas de qualquer pagamento compensatório. Em 1761 havia mais de 50 alunos a assistirem às lições de música na Patriarcal (FERNANDES, 2013, p.30), e tais aulas vespertinas funcionaram até o final da existência desta instituição (VIEIRA, 1900, v.1, p.550). Foi muito provavelmente nesta condição de aluno externo do Seminário da Patriarcal que André da Silva Gomes tomou aulas de música com José Joaquim dos Santos, sem ter que se vincular a uma ordenação religiosa. A idade de admissão e permanência em situações estatutárias comuns seria compatível. Se Gomes entrou ao tempo que Santos passou a lecionar, tinha por volta dos nove anos de idade em janeiro de 1763.

O Seminário da Patriarcal parece ter sido muito influenciado pelos moldes estabelecidos nos conservatórios napolitanos, até porque músicos portugueses também estudaram em Nápoles. Embora o caso de Gomes surja aqui como exemplo pontual de um processo de formação, com clara linhagem de antecedentes, em que o músico é ensinado numa perspectiva teórico-prática do aprendizado, ele encontra outros paralelos importantes no Brasil. Luís Alvares Pinto (c.1719-1789), José Maurício Nunes Garcia (1767-1830) e João de Deus Castro Lobo (1794-1832), por exemplo, também 
estudaram Filosofia Moral e Retórica, deixando claro proveito disso em suas respectivas obras. O mais importante no momento atual da pesquisa sobre estes autores do citado período entre Setecentos e Oitocentos tem sido perceber que o processo de formação de um músico acontecia em um viés criativo-interpretativo, não apenas atento à técnica; tal formação era feita com a consciência de que o músico é aquele que maneja uma linguagem, da elaboração à execução, e de que precisa ter preparo adequado ao processo de transformação das ideias em expressão, o que eleva seu projeto musical ao nível de projeto poético. O músico como retórico é a idealização de um artista como artesão eintelectual de ideias, palavras e ação, a serviço da comunicação de sentimentos e expressões.

\section{Referências}

ALLANBROOK, Wye Jamison. Rhythmic gesture in Mozart: le nozze di Figaro and Don Giovanni. Chicago: University of Chicago Press, 1983.

ALLANBROOK, Wye Jamison. The secular commedia: comic mimesis in late eighteenth century music. Oakland: University of California Press, 2014.

BLUTEAU, Raphael. Vocabulario portuguez, e latino, aulico, anatomico, architectonico, bellico, botanico ... : autorizado com exemplos dos melhores escritores portuguezes , e latinos; e offerecido a El Rey de Portugal D. Joaõ V. Coimbra, Collegio das Artes da Companhia de Jesu : Lisboa, Officina de Pascoal da Sylva, 1712-1728. 8 v., 2 suplementos.

BURMEISTER, Joachim. Hypomnematum Musica Poetica. Rostock: Myliander, 1599.

BYROS, Vasili. Foundations of tonality as situated cognition, 1730-1830: An enquiry into the culture and cognition of eighteenth-century tonality, with Beethoven's "Eroica" symphony as a case study. Thesis ( Ph.D. Music Theory) - Yale University, New Haven, 2009.

BYROS, Vasili. Topics and harmonic schemata: a case from Beethoven. In: MIRKA, Danuta (ed.). The Oxford Handbook of Topic Theory. New York: Oxford University Press, 2014. p. 381-414.

CHRISTOVAM, Ozório Bimbato Pereira. Música sacra, discurso e poder: modelos précomposicionais na missa luso-brasileira. Tese (Doutorado) - USP, São Paulo, 2017.

DUPRAT, Régis. Música na Sé Colonial de São Paulo. São Paulo: Paulus, 1995.

DUPRAT et al. Arte explicada do contraponto. São Paulo: Arte \& Ciência, 1998. 
FERNANDES, Cristina. "Boa voz de tiple, sciencia de música e prendas de acompanhamento", o real seminário da patriarcal: 1713-1834. Lisboa: BNP/Inet, 2013.

FORKEL, Johann N. Allgemeine Geschichte der Music. Leipzig: Schwickert, 1788-1801.

GJERDINGEN, Robert O. Music in the Galant Style. Oxford; New York: Oxford University Press, 2007.

HEARTZ, Daniel. Music in European Capitals: the Galant Style, 1720-1780. New York; London: Norton, 2003.

KIRCHER, Athanasius. Musurgia universalis sive ars magna consoni et dissoni. Roma: Ex typographia Haeredum Francisci Corbelletti, 1650.

KISIELEWSKA, Olga Sánchez. Interactions between topics and schemata: the case of the Sacred Romanesca. Theory and Practice, v. 41, p. 47-80, 2016.

LANDI, Marcio Spártaco. Lições de contraponto segundo a arte explicada de André da Silva Gomes. Fortaleza: Expressão Gráfica, 2006.

MATTHESON, Johann. Das neu-Eroffnete Orchestre. Hamburgo: Benjamin Schillers Witwe, 1713.

MATTHESON, Johann. Der Volkommene Capellmeister. Hamburgo: Christian Herold, 1739. Reimpr. Kassel: Baerenreiter, 1954.

MEYER, Leonard B. Emotion and Meaning in Music. Chicago: The University of Chicago Press, 1956.

MEYER, Leonard B. Style and Music. Theory, history and ideology. Philadelphia: University of Pennsylvania Press, 1989.

MIRKA, Danuta (org.). The Oxford handbook of topics. Oxford: Oxford University Press, 2014.

MIRKA, Danuta; AGAWU, Kofi (ed.). Communication in Eighteenth-Century Music. Cambridge: Cambridge University Press, 2008.

MONELLE, Raymond. The Musical Topic: hunt, military and pastoral. Bloomington; Indianapolis: Indiana University Press, 2006.

PALUMBO, Lidia. Mimesis. Rappresentazione, teatro e mondo nei dialoghi di platone e nella poética do aristotele. Napoli: Loffredo editore, 2008. 
RAMEAU, Jean-Phillippe. Traité de l'harmonie reduit a ses príncipes naturels. Paris: Ballard, 1722.

RAMOS, Rafael Registro. Discurso e conceitos no tratado de contraponto de André da Silva Gomes. Dissertação de Mestrado (USP). São Paulo: 2014.

RATNER, Leonard G. Music: the listener's art. New York: McGraw-Hill, 1957.

RATNER, Leonard G. Music: the listener's art. 2. ed. New York: McGraw-Hill, 1966.

RATNER, Leonard G. Classic music: expression, form, and style. New York: Schirmer, 1980.

ROUSSEAU, Jean Jacques. Lettre sur la musique française. Paris: [s. n.], 1753.

ROUSSEAU, Jean Jacques. La nouvelle Heloise, ou Lettres de deux amans [i.e. amants], habitans [i.e. habitants] d'une petite ville au pied des Alpes. Recueillies et publiées par J.J. Rousseau. Neuchatel; Paris: Duchesne, 1764. (Parte primeira)

RUMPH, Stephen. Mozart and Enlightenment Semiotics. Berkeley: University of California Press, 2012.

SANGUINETTI, Giorgio. The art of partimento: history, theory and practice. Oxford: Oxford University Press, 2012.

SILVA, Antonio Moraes. Diccionario da lingua portugueza composto pelo padre $D$. Rafael Bluteau, reformado, e accrescentado por Antonio de Moraes Silva natural do Rio de Janeiro. Lisboa: Officina de Simao Thadeo Ferreira, 1789.

SULZER, Johann Georg Sulzer. Allgemeine Theorie der Schonen Kunste. Leipzig: Weidmann, 1792-1794. 4 v. Reimp. Hildesheim: Georg Olms, 1994.

TRILHA, Mario Marques. Teoria e prática do baixo contínuo em Portugal (1735-1820). Tese (Doutorado em Música) - Universidade de Aveiro, Aveiro, 2010.

VIEIRA, Ernesto. Diccionario Biographico dos Musicos Portuguezes. Lisboa: Typ. Mattos, Moreira \& Pinheiro, 1900. 2v. 